\title{
INCORPORATION OF A TWO-FLUX MODEL FOR RADIATIVE HEAT TRANSFER IN A COMPREHENSIVE FLUIDIZED BED SIMULATOR \\ PART I: PRELIMINARY THEORETICAL INVESTIGATIONS
}

\author{
J. A. Rabi and M. L. de \\ Souza Santos \\ Universidade Estadual de Campinas \\ Faculdade de Engenharia Mecânica \\ Departamento de Energia \\ Caixa Postal 6122 \\ 13087-970, Campinas, SP, Brasil \\ jrabi@fem.unicamp.br \\ dss@fem.unicamp.br

\begin{abstract}
Over the last two decades, a comprehensive mathematical model and its corresponding computational program, aimed to simulate steady-state operations of bubbling fluidized bed equipments, has been continuously improved and tested. Despite its success, the simulator has employed a simple approach for radiative heat transfers. In cases of high temperatures, thermal radiation becomes an important energy transfer mode and the original model could lead to deviations above acceptable levels. The purpose of the present work was to improve the model for thermal radiation heat transfer between all solid particles in the bed section by applying a two-flux method to a non-homogeneous polydispersed particulate media in radiative equilibrium. Gases in the emulsion and in the bubbles were assumed transparent to thermal radiation. This first part of the paper presents and discusses the basic structure of the former mathematical model and of the new one.
\end{abstract}

\section{INTRODUCTION}

Fluidized bed equipments are employed in many industrial processes such as combustion and gasification. Among their advantages over more conventional technologies, one can mention bed temperature control and uniformity, low pollutant emission rates, high turndown ratios and relatively high heat-transfer coefficients between bed material and immersed tubes.

Since experimentation is more expensive than computation, modeling and simulation of fluidized-bed equipment play a major role in design and optimization. Moreover, numerical procedures may be the only permissible way to explore limiting situations due to safety concerns. Hence, a comprehensive mathematical model and computer program should cover important aspects of the process in order to be able to predict parameters that describe the operation of the equipment.

Over the last 20 years, a comprehensive simulation program for bubbling fluidized bed equipments has been improved and tested against experimental data (de Souza-Santos, 1987). At its present stage, the mathematical model includes up to 100-coupled differential equations for mass and energy balances. A large number of those were incorporated in later versions of the program (de Souza Santos, 1989, 1992, 1993, 1994, 1995, 1996, 1997, 1998 and 1999), which evidences the dynamic feature of the simulation program, namely its ability to be extended and updated with newly published information.

In systems where high temperature levels are achieved, such as in boilers and gasifiers, thermal radiation is an important heat transfer mode. Despite its success, the present version of the simulator has employed a simple approach for it. Therefore, further improvements are possible. This work intends to accomplish that, mainly for the treatment of radiative heat transfers between solid particles in the bed section.
In order to preserve the basic structure of the original mathematical model and simulation program, a two-flux approach was applied to a non-homogeneous polydispersed particulate media in radiative equilibrium. The choice of such method comes also from the fact that thermal radiation in participating media is governed by an integro-differential equation. The addition of such equations in the model would bring great difficulties for the mathematical solutions of differential systems of equations. The flux models use approximations for the directional dependence of radiation intensity, therefore allowing integro-differential equations to be replaced by a set of differential ones.

\section{BASIC DESCRIPTION OF THE CURRENT MATHEMATICAL MODEL}

The simulator considers steady-state operations of bubbling fluidized bed equipments. Another major assumptions are (de Souza-Santos, 1987, 1989):

- Axial plug-flow regimes for ascending gas in bubbles and gas percolating the particles in the emulsion. Hence, all physical quantities and operational parameters for gas phases are function of the bed height $\mathrm{z}$ alone.

- Bubbles are free of particles. Therefore, the emulsion contains all particles plus the percolating gas.

- Solid particles move randomly in the bed.

Figure 1 shows a schematic representation of typical fluidized bed equipment simulated. 
CIÊNCIA/SCIENCE

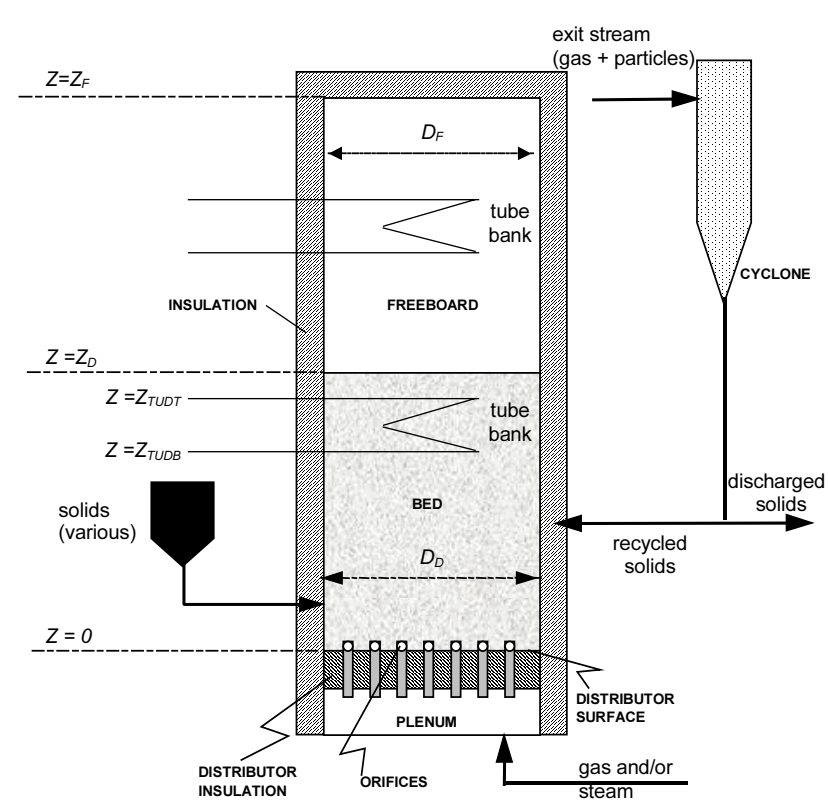

Figure 1. Schematic representation of a typical fluidized bed equipment simulated

In general, carbonaceous solids are continuously fed into the bed. Other species present in the emulsion phase are interstitial gas, inert material and limestone. The bubble phase is free of solid particles and the clouds are incorporated in the emulsion phase. Plug-flow regimes are assumed for the gas in the bubble and for the interstitial gas in the emulsion. This kind of flow is also assumed for the gas flow in the freeboard.

At the bed base $(z=0)$, the only set of boundary conditions completely known refers to the gas stream injected through the distributor. Boundary conditions for the lowest part of the freeboard correspond to the exiting conditions at the bed top. However, boundary conditions for the temperature of each individual solid species at the bed base are given by a convergence routine based on the heat fluxes transferred by convection and by conduction at $z=0$.

The basic system of differential equations resulting from the mass and energy balances throughout the bed and freeboard sections as well as the simulation strategy can be found in the forerunner work (de SouzaSantos, 1987) and in later versions (de Souza Santos, 1989, 1992, 1993, 1994, 1995, 1996, 1997, 1998, 1999).

\section{Energy balances and heat transfers in the bed section: original model}

The comprehensive simulation model takes into account many heat transfer modes occurring inside the equipment, involving different phases, namely between:

- Gas in the bubbles and in the emulsion;

- Solids and gas in the emulsion and in the freeboard;

- Solids in the emulsion and in the freeboard;

- Tube banks and gas in the bubbles and/or in the emulsion in the bed section;

- Tube banks and gas in the freeboard section;

- Tube banks and solids in the bed and in the freeboard section;

- Distributor plate and the bed;

- Inner reactor walls and the bed;

\section{J. A. Rabi et al. Incorporation of a Two-Flux...}

- Inner reactor walls and gas in the freeboard;

- Outer reactor walls and the environment;

- Inner tube walls in the bed or in the freeboard section and water (liquid or vapor) inside.

The energy balance for a $m$-type solid ( $m=1$ for carbonaceous, $m=2$ for limestone and $m=3$ for inert) in the emulsion (bed section) is expressed by:

$$
\begin{aligned}
F_{\mathrm{SE}, \mathrm{m}} c_{\mathrm{S}, \mathrm{m}} \frac{\mathrm{d} T_{\mathrm{SE}, \mathrm{m}}}{\mathrm{d} z}= & -E_{\mathrm{Q}, \mathrm{SE}, \mathrm{m}}-E_{\mathrm{M}, \mathrm{SEGE}, \mathrm{m}}-E_{\mathrm{C}, \mathrm{SEGE}, \mathrm{m}} \\
& -\sum_{\mathrm{n}=1}^{3} E_{\mathrm{C}, \mathrm{SESE}, \mathrm{m}, \mathrm{n}}-\sum_{\mathrm{n}=1}^{3} E_{\mathrm{R}, \mathrm{SESE}, \mathrm{m}, \mathrm{n}} \\
& -E_{\mathrm{R}, \mathrm{SETD}, \mathrm{m}}-E_{\mathrm{R}, \mathrm{SEWD}, \mathrm{m}}
\end{aligned}
$$

where $F_{\mathrm{SE}, \mathrm{m}}$ is the solid mass flow $\left(\mathrm{kg} . \mathrm{s}^{-1}\right), \quad c_{\mathrm{S}, \mathrm{m}}$ its specific heat $\left(\mathrm{J}^{\mathrm{kg}} \mathrm{kg}^{-1} \cdot \mathrm{K}^{-1}\right)$ and $T_{\mathrm{SE}, \mathrm{m}}$ its temperature $(\mathrm{K})$. The meaning of each energy source or sink term $\left(\mathrm{W} . \mathrm{m}^{-1}\right)$ on the right hand side of the Eq. (1) is

- $E_{\mathrm{Q}, \mathrm{SE}, \mathrm{m}}=$ energy released from solid surface chemical reactions;

- $\quad E_{\mathrm{M}, \mathrm{SEGE}, \mathrm{m}}=$ energy transferred between solids and gas due to mass transfer;

- $E_{\mathrm{C}, \mathrm{SEGE}, \mathrm{m}}=$ energy transferred through convection between solids and gas;

- $E_{\mathrm{C}, \mathrm{SESE}, \mathrm{m}, \mathrm{n}}=$ energy transferred through convection between solids $m$ and solids $n$;

- $E_{\mathrm{R}, \mathrm{SETD}, \mathrm{m}}=$ energy transferred through thermal radiation between solids and tubes in the bed section;

- $E_{\mathrm{R}, \mathrm{SEWD}, \mathrm{m}}=$ energy transferred through thermal radiation between solids and reactor walls in the bed section;

- $E_{\mathrm{R}, \mathrm{SESE}, \mathrm{m}, \mathrm{n}}=$ energy transferred through thermal radiation between solids $m$ and solids $n$.

A similar equation holds for solids in the freeboard. As a model simplification, gas phases in the emulsion and in the bubbles are assumed transparent to thermal radiation. Hence, there is no radiative heat transfer term such as $E_{\mathrm{R}, \mathrm{SEGE}, \mathrm{m}}$.

\section{original model \\ Radiative heat transfer between solids:}

Radiative heat exchange between the various solids in the emulsion is calculated as

$$
E_{\mathrm{R}, \mathrm{SESE}, \mathrm{m}, \mathrm{n}}=\bar{\varepsilon}_{\mathrm{SE}} \sigma\left(T_{\mathrm{SE}, \mathrm{m}}^{4}-T_{\mathrm{SE}, \mathrm{n}}^{4}\right) f_{\mathrm{n}}^{\prime \prime} \frac{\mathrm{d} A_{\mathrm{SE}, \mathrm{m}}}{\mathrm{d} z}
$$

where $\sigma$ is the Stefan-Boltzmann constant and $\mathrm{d} A_{\mathrm{SE}, \mathrm{m}}$ is the total particle surface area in a differential bed section of length $\mathrm{d} z$. The "average" emissivity $\bar{\varepsilon}_{\mathrm{SE}}$ is defined in terms of the area fraction $f^{\prime \prime}$ and emissivity $\varepsilon_{\mathrm{S}}$ of the corresponding solid species, according to

$$
\frac{1}{\bar{\varepsilon}_{\mathrm{SE}}}=f_{\mathrm{n}}^{\prime \prime} \frac{1-\varepsilon_{\mathrm{S}, \mathrm{m}}}{\varepsilon_{\mathrm{S}, \mathrm{m}}}+f_{\mathrm{m}}^{\prime \prime} \frac{1-\varepsilon_{\mathrm{S}, \mathrm{n}}}{\varepsilon_{\mathrm{S}, \mathrm{n}}}+1
$$

The model assumes that the $m$-type particles are surrounded by particles of all types and therefore they "see" $n$-type particles through an area fraction $f_{n}$ ". In analogy, for the "reverse" radiative heat transfer it is possible to write. 


$$
E_{\mathrm{R}, \mathrm{SESE}, \mathrm{n}, \mathrm{m}}=\bar{\varepsilon}_{\mathrm{SE}} \sigma\left(T_{\mathrm{SE}, \mathrm{n}}^{4}-T_{\mathrm{SE}, \mathrm{m}}^{4}\right) f_{\mathrm{m}}^{\prime \prime} \frac{\mathrm{d} A_{\mathrm{SE}, \mathrm{n}}}{\mathrm{d} z}
$$

In order to establish a relationship between Eqs. (2) and (4), the definitions for $\left(\mathrm{d} A_{\mathrm{SE}, \mathrm{m}} / \mathrm{d} z\right),\left(\mathrm{d} A_{\mathrm{SE}, \mathrm{n}} / \mathrm{d} z\right)$, $f_{\mathrm{m}}{ }^{\prime \prime}$ and $f_{\mathrm{n}}^{\prime \prime}$ should be evoked. In original model, the first two quantities are given by

$$
\begin{aligned}
& \frac{\mathrm{d} A_{\mathrm{SE}, \mathrm{m}}}{\mathrm{d} z}=S_{\mathrm{E}}\left(1-\mathrm{v}_{\mathrm{E}}\right) f_{\mathrm{m}}^{\prime \prime \prime} \frac{A_{\mathrm{SE}, \mathrm{m}}}{V_{\mathrm{SE}, \mathrm{m}}} \\
& \frac{\mathrm{d} A_{\mathrm{SE}, \mathrm{n}}}{\mathrm{d} z}=S_{\mathrm{E}}\left(1-\mathrm{v}_{\mathrm{E}}\right) f_{\mathrm{n}}^{\prime \prime \prime} \frac{A_{\mathrm{SE}, \mathrm{n}}}{V_{\mathrm{SE}, \mathrm{n}}}
\end{aligned}
$$

whereas

$$
f_{\mathrm{m}}^{\prime \prime}=\frac{f_{\mathrm{m}}^{\prime} A_{\mathrm{SE}, \mathrm{m}}}{\sum_{\mathrm{k}} f_{\mathrm{k}}^{\prime} A_{\mathrm{SE}, \mathrm{k}}} \quad \text { and } \quad f_{\mathrm{n}}^{\prime \prime}=\frac{f_{\mathrm{n}}^{\prime} A_{\mathrm{SE}, \mathrm{n}}}{\sum_{\mathrm{k}} f_{\mathrm{k}}^{\prime} A_{\mathrm{SE}, \mathrm{k}}}
$$

where $S_{\mathrm{E}}$ is the emulsion cross sectional area and $v_{\mathrm{E}}$ the emulsion void fraction. For the $m$-type particles in the emulsion, $A_{\mathrm{SE}, \mathrm{m}}$ and $V_{\mathrm{SE}, \mathrm{m}}$ are their total surface area and total occupied volume respectively whereas $f_{\mathrm{m}}{ }^{\prime}$ and $f_{\mathrm{m}}{ }^{\prime \prime}$ are their number and volume fractions in this order. In the model, these fractions are calculated as

$$
f_{\mathrm{m}}^{\prime}=\frac{\left(f_{\mathrm{m}}^{\prime \prime \prime} / V_{\mathrm{SE}, \mathrm{m}}\right)}{\sum_{\mathrm{k}}\left(f_{\mathrm{k}}^{\prime \prime \prime} / V_{\mathrm{SE}, \mathrm{k}}\right)} \quad \text { and } \quad f_{\mathrm{m}}^{\prime \prime \prime}=\frac{\left(f_{\mathrm{m}} / \rho_{\mathrm{S}, \mathrm{m}}\right)}{\sum_{\mathrm{k}}\left(f_{\mathrm{k}} / \rho_{\mathrm{S}, \mathrm{k}}\right)}
$$

Here, $\rho_{\mathrm{s}, \mathrm{m}}$ is $m$-type solid density and $f_{\mathrm{m}}$ is its corresponding mass fraction, obtained from the mass fraction referred to the particle size distribution (de SouzaSantos, 1987).

After some algebraic manipulations, it is possible to demonstrate that

$$
f_{\mathrm{n}}^{\prime \prime} \frac{\mathrm{d} A_{\mathrm{SE}, \mathrm{m}}}{\mathrm{d} z}=f_{\mathrm{m}}^{\prime \prime} \frac{\mathrm{d} A_{\mathrm{SE}, \mathrm{n}}}{\mathrm{d} z}
$$

This equation is much like a "law of reciprocity for view factors", commonly encountered in radiative heat transfer problems (Brewster, 1992 and Modest, 1993). An important mathematical consequence of inserting the above relation back into Eq. (2) and comparing the resulting equation to Eq. (4) is that

$E_{\mathrm{R}, \mathrm{SESE}, \mathrm{m}, \mathrm{n}}=-E_{\mathrm{R}, \mathrm{SESE}, \mathrm{n}, \mathrm{m}} \Leftrightarrow E_{\mathrm{R}, \mathrm{SESE}, \mathrm{m}, \mathrm{n}}+E_{\mathrm{R}, \mathrm{SESE}, \mathrm{n}, \mathrm{m}}=0$

The total radiative heat transfer $E_{\mathrm{R}, \mathrm{SESE}, \mathrm{m}}$ concerning the $m$-type particles is the sum

$$
E_{\mathrm{R}, \mathrm{SESE}, \mathrm{m}}=\sum_{\mathrm{n}=1}^{3} E_{\mathrm{R}, \mathrm{SESE}, \mathrm{m}, \mathrm{n}}
$$

Because of Eq. (10), at any bed position $z$ the sum of all radiative heat transfer terms $E_{\mathrm{R}, \mathrm{SESE}, \mathrm{m}}$ equals zero, i.e.,

$$
\sum_{\mathrm{m}=1}^{3} E_{\mathrm{R}, \mathrm{SESE}, \mathrm{m}}=\sum_{\mathrm{m}=1 \mathrm{n}=1}^{3} \sum_{\mathrm{R}, \mathrm{SESE}, \mathrm{m}, \mathrm{n}}^{3}=0
$$

since the 9 terms taking part in the above double summation, either cancels each other or are identically null (which is the case of the 3 terms $E_{\mathrm{R}, \mathrm{SESE}, \mathrm{m}, \mathrm{m}}$ ).

The condition stated by Eq. (11) establishes a "conservation" of the thermal radiation exchanged among the solids. In other words, at a given position $z$ in the bed, the local physical conditions (particle temperature, number fraction, area fraction, volume fraction) determine the amount of thermal radiation to be exchanged between particles.

\section{RADIATIVE HEAT TRANSFER IN PARTICIPATING MEDIA}

As far as the computational program is concerned, it is assumed that Eq. (11) is a condition to be imposed by convergence. Such condition would also be applied in the improvements of the simulation regarding radiative heat transfer between solids. The new approach follows a twoflux model, which is incorporated to the simulation model. Therefore, the thermal radiation terms $E_{\mathrm{R}, \mathrm{SESE}, \mathrm{m}}$ are conveniently redefined as to preserve Eq. (11).

\section{Thermal radiation within monodispersed participating media}

Radiative heat transfer with participating media is governed by an integro-differential equation known as the transfer equation. It represents the radiative energy balance on a differential volume element along a given line of sight. As sketched in Fig. 2, it provides a balance for the radiation intensity $I$ (W. $\left.\mathrm{m}^{-2} \cdot \mathrm{sr}^{-1}\right)$ as it travels through a distance $\mathrm{dl}$ in participating media. Three processes influence this balance: absorption, emission and scattering.

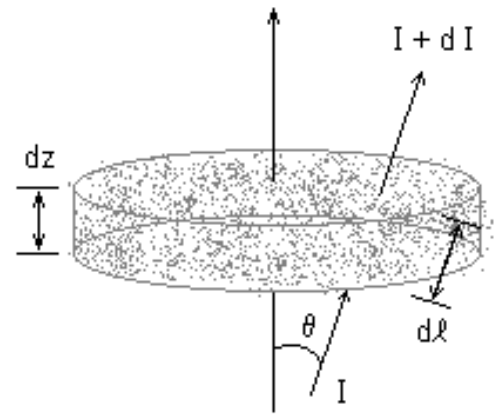

Figure 2. Radiative intensity variation across a planeparallel particulate system.

In order to preserve the basic structure of the original mathematical model and simulation program, axial symmetry was evoked. Therefore, the intensity $I$ at any point becomes independent of the azimuth angle $\psi$. However, it may still depend on the polar angle $\theta$ measured from the $z$-axis. Following other investigators (Modest, 1993), isotropic scattering was assumed as well. Under all these assumptions and introducing $\mu=\cos \theta$ and $\mathrm{d} z=\mathrm{dl} \cos \theta$, the transfer equation for a plane-parallel media (composed by a single solid type) is expressed as

$$
\mu \frac{\mathrm{d} I(z, \mu)}{\mathrm{d} z}=-\left(K_{\mathrm{a}}+K_{\mathrm{s}}\right) I(z, \mu)+K_{\mathrm{a}} \frac{\sigma T^{4}}{\pi}+\frac{K_{\mathrm{s}}}{4 \pi} G(z)
$$

where $K_{\mathrm{a}}$ and $K_{\mathrm{s}}\left(\mathrm{m}^{-1}\right)$ are respectively the absorption and scattering coefficients and $T=T(z)$ is the local particle temperature. The quantity

$$
G=G(z)=\int_{4 \pi} I \mathrm{~d} \Omega=2 \pi \int_{-1}^{1} I(z, \mu) \mathrm{d} \mu
$$

is referred to as the incident radiation function and corresponds to the total intensity impinging on a point from all incoming directions, i.e., over the entire solid angle $\Omega=4 \pi \mathrm{sr}$. Note that $I=I(z, \theta)$ and also that $\mathrm{d} \Omega=$ 
$2 \pi \operatorname{sen} \theta \mathrm{d} \theta$, in accordance to the axial symmetry assumption.

Consider a surface element whose outward normal is $\hat{n}$, as sketched in Fig. 3 .

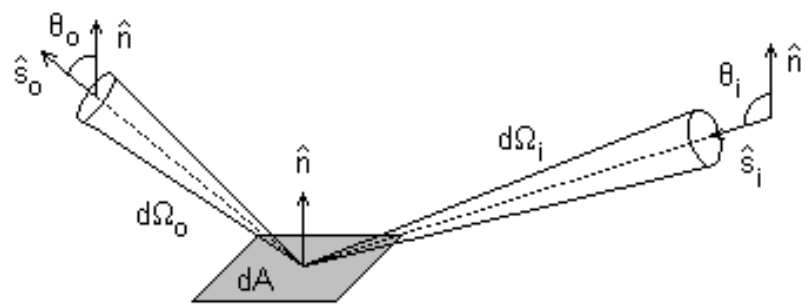

Figure 3. Radiative heat flux into and out of a surface.

The radiative flux onto an orthogonal surface projection $\mathrm{d} A_{\perp}=\mathrm{d} A \cos \theta$ is negative, whereas the radiative flux out of this surface element is positive. The net flux $\vec{q}$ can be expressed in terms of incident and outgoing intensity as

$$
\vec{q} \cdot \hat{n}=\int_{4 \pi} I \hat{n} \cdot \hat{s} \mathrm{~d} \Omega=2 \pi \int_{-1}^{1} I(z, \mu) \mu \mathrm{d} \mu
$$

If energy balances are to be considered for the particulate media, attention should be assigned to the net radiative energy per unit volume and per unit time leaving a differential volume element in the bed. This quantity is represented by the divergence of the radiative flux vector, Eq. (14), and may be obtained by integrating Eq. (12) over the full $4 \pi \mathrm{sr}$ solid angle range. The result, demonstrated elsewhere (Brewster, 1992; Modest, 1993), is

$$
\nabla \cdot \vec{q}=\frac{\mathrm{d} q}{\mathrm{~d} z}=K_{\mathrm{a}}\left(4 \sigma T^{4}-G\right)
$$

Independent absorption and scattering were also assumed. Thus, particles interact with incident radiation without being influenced by the surrounding ones. According to regime maps presented by Brewster and Tien (1982), Tien (1988), Brewster (1992) and Modest (1993), that is a very good approximation when applied to typical operations of fluidized bed equipments. Those maps are based on particle diameter, particle center-to-center distance and incident wavelength. As a result, absorption and scattering coefficients $K_{\mathrm{a}}$ and $K_{\mathrm{s}}$ are obtained by adding single-particle properties. As pointed by Shafey et al. (1993), considering usual thermal radiation wavelengths and particle sizes found in fluidized beds, geometric optics results can be employed.

For a monodispersed fluidized bed of spherical opaque solids in the large particle limit, the expressions for absorption and scattering coefficients for a given solid species $m$ are respectively (Brewster, 1992)

$$
\begin{aligned}
& K_{\mathrm{a}, \mathrm{m}}=\frac{1.5 f_{\mathrm{V}, \mathrm{SE}, \mathrm{m}} \varepsilon_{\mathrm{S}, \mathrm{m}}}{d_{\mathrm{S}, \mathrm{m}}} \text { and } \\
& K_{\mathrm{s}, \mathrm{m}}=\frac{1.5 f_{\mathrm{V}, \mathrm{SE}, \mathrm{m}}\left(1-\varepsilon_{\mathrm{S}, \mathrm{m}}\right)}{d_{\mathrm{S}, \mathrm{m}}}
\end{aligned}
$$

where $f_{\mathrm{V}, \mathrm{SE}, \mathrm{m}}$ is the fraction of emulsion volume occupied by the $m$-type solids, whose diameter $d_{\mathrm{S}, \mathrm{m}}$ is supposed to be constant. It should be mentioned that this fraction do not correspond to the volume fraction $f_{\mathrm{m}}^{\prime \prime \prime}$ previously introduced.

\section{Thermal radiation within polydispersed heterogeneous participating media}

When the bed is composed by particles of different sizes, polydispersion effects take place. For a $m$ type solid, the supposed constant particle diameter $d_{\mathrm{S}, \mathrm{m}}$ in Eqs. (16) must be replaced by a mean diameter $d_{32, \mathrm{~m}}$, defined in terms of its corresponding radius $r_{32, \mathrm{~m}}=d_{32, \mathrm{~m}} / 2$ , as suggested by Brewster (1992),

$$
r_{32, \mathrm{~m}}=\frac{\int_{0}^{\infty} r_{\mathrm{m}}^{3} n_{\mathrm{m}}(r) \mathrm{d} r}{\int_{0}^{\infty} r_{\mathrm{m}}^{2} n_{\mathrm{m}}(r) \mathrm{d} r}=\frac{\int_{0}^{\infty} r_{\mathrm{m}}^{3} N_{\mathrm{m}}(r) \mathrm{d} r}{\int_{0}^{\infty} r_{\mathrm{m}}^{2} N_{\mathrm{m}}(r) \mathrm{d} r}
$$

where $\quad n_{\mathrm{m}}(r)=N_{\mathrm{m}}(r) / V_{\mathrm{E}} \quad$ is the number of $m$-type particles per unit of emulsion volume, whose radius lies between $r$ and $r+\mathrm{d} r$.

In the simulation program, the above integrals are numerically evaluated. At a given bed height $z$, the total particle mass $M_{\mathrm{m}}$ obeys the following relations:

$$
M_{\mathrm{m}}=\sum_{\mathrm{i}} N_{\mathrm{m}, \mathrm{i}} M_{\mathrm{m}, \mathrm{i}} \Leftrightarrow 1=\sum_{\mathrm{i}} \frac{N_{\mathrm{m}, \mathrm{i}} M_{\mathrm{m}, \mathrm{i}}}{M_{\mathrm{m}}}=\sum_{\mathrm{i}} x_{\mathrm{m}, \mathrm{i}}
$$

where $x_{\mathrm{m}, \mathrm{i}}=N_{\mathrm{m}, \mathrm{i}} M_{\mathrm{m}, \mathrm{i}} / M_{\mathrm{m}}$ is the mass fraction of the $N_{\mathrm{m}, \mathrm{i}}$ particles belonging to the $i$-th Tyler mesh opening. Assuming constant particle density $\rho_{\mathrm{S}, \mathrm{m}}$, it follows that

$$
\frac{M_{\mathrm{m}, \mathrm{i}}}{M_{\mathrm{m}}}=x_{\mathrm{m}, \mathrm{i}}=N_{\mathrm{m}, \mathrm{i}} \frac{4}{3} \frac{\rho_{\mathrm{S}, \mathrm{m}} \pi \tilde{r}_{\mathrm{i}}^{3}}{M_{\mathrm{m}}} \Rightarrow N_{\mathrm{m}, \mathrm{i}}=\frac{3 M_{\mathrm{m}} x_{\mathrm{m}, \mathrm{i}}}{4 \rho_{\mathrm{S}, \mathrm{m}} \pi \widetilde{r}_{\mathrm{i}}^{3}}
$$

Here, $\tilde{r}_{\mathrm{i}}$ is the average radius of the $i$-th size interval. Then, a discrete evaluation of $r_{32, \mathrm{~m}}$ is

$$
r_{32, \mathrm{~m}}=\frac{\sum_{\mathrm{i}} \widetilde{r}_{\mathrm{i}}^{3} N_{\mathrm{m}, \mathrm{i}}}{\sum_{\mathrm{i}} \widetilde{r}_{\mathrm{i}}^{2} N_{\mathrm{m}, \mathrm{i}}}=\frac{\sum_{\mathrm{i}} \tilde{r}_{\mathrm{i}}^{3} \frac{3 M_{\mathrm{m}} x_{\mathrm{m}, \mathrm{i}}}{4 \rho_{\mathrm{S}, \mathrm{m}} \pi \widetilde{r}_{\mathrm{i}}^{3}}}{\sum_{\mathrm{i}} \tilde{r}_{\mathrm{i}}^{2} \frac{3 M_{\mathrm{m}} x_{\mathrm{m}, \mathrm{i}}}{4 \rho_{\mathrm{S}, \mathrm{m}} \pi \widetilde{r}_{\mathrm{i}}^{3}}}=\frac{1}{\sum_{\mathrm{i}} \frac{x_{\mathrm{m}, \mathrm{i}}}{\tilde{r}_{\mathrm{i}}}}
$$

This result shows that the average diameter $d_{32, \mathrm{~m}}$ necessary for the calculation of absorption and scattering coefficients, corresponds to the very same average diameter $\bar{d}_{\mathrm{S}, \mathrm{m}}$, as defined in most texts on fluidization theory (Kunii and Levenspiel, 1969; Geldart, 1986), or

$$
d_{32, \mathrm{~m}}=\frac{1}{\sum_{\mathrm{i}} \frac{x_{\mathrm{m}, \mathrm{i}}}{\widetilde{d}_{\mathrm{i}}}}=\bar{d}_{\mathrm{S}, \mathrm{m}}
$$

Moreover, for each solid species $m$, it is possible to relate the distinct volume fractions $f_{\mathrm{V}, \mathrm{SE}, \mathrm{m}}$ (needed for the evaluation of optical coefficients) and $f_{\mathrm{m}}^{\prime \prime \prime}$. If $V_{\mathrm{GE}}$ and $V_{\mathrm{SE}}$ are, respectively, the volume occupied by the gas phase and the solids in the emulsion, the total volume of emulsion is simply $V_{\mathrm{E}}=V_{\mathrm{GE}}+V_{\mathrm{SE}}$, and

$$
1-v_{\mathrm{E}}=1-\frac{V_{\mathrm{GE}}}{V_{\mathrm{E}}}=\frac{V_{\mathrm{E}}-V_{\mathrm{GE}}}{V_{\mathrm{E}}}=\frac{V_{\mathrm{SE}}}{V_{\mathrm{E}}}=f_{\mathrm{V}, \mathrm{SE}}
$$

where $f_{\mathrm{V}, \mathrm{SE}}$ is the fraction of the emulsion volume occupied by all particles. On the other hand, 


$$
V_{\mathrm{SE}}=\sum_{\mathrm{m}=1}^{3} V_{\mathrm{SE}, \mathrm{m}} \quad \Leftrightarrow \quad 1=\sum_{\mathrm{m}=1}^{3} \frac{V_{\mathrm{SE}, \mathrm{m}}}{V_{\mathrm{SE}}}=\sum_{\mathrm{m}=1}^{3} f_{\mathrm{m}}^{\prime \prime \prime}
$$

and the desired relation is then obtained as

$$
f_{\mathrm{m}}^{\prime \prime \prime}\left(1-\mathrm{v}_{\mathrm{E}}\right)=f_{\mathrm{m}}^{\prime \prime \prime} f_{\mathrm{V}, \mathrm{SE}}=\frac{f_{\mathrm{m}}^{\prime \prime \prime} V_{\mathrm{SE}}}{V_{\mathrm{E}}}=\frac{V_{\mathrm{SE}, \mathrm{m}}}{V_{\mathrm{E}}}=f_{\mathrm{V}, \mathrm{SE}, \mathrm{m}}
$$

The absorption and scattering coefficients for a given solid type $m$ in a monodispersed particulate media, Eqs. (16), may now be replaced by their polydispersion counterparts, or

$$
\begin{aligned}
K_{\mathrm{a}, \mathrm{m}} & =\frac{1.5 f_{\mathrm{m}}^{\prime \prime \prime}\left(1-\mathrm{v}_{\mathrm{E}}\right) \varepsilon_{\mathrm{S}, \mathrm{m}}}{\bar{d}_{\mathrm{S}, \mathrm{m}}} \text { and } \\
K_{\mathrm{s}, \mathrm{m}} & =\frac{1.5 f_{\mathrm{m}}^{\prime \prime \prime}\left(1-\mathrm{v}_{\mathrm{E}}\right)\left(1-\varepsilon_{\mathrm{S}, \mathrm{m}}\right)}{\bar{d}_{\mathrm{S}, \mathrm{m}}}
\end{aligned}
$$

Since volumetric fractions are independent and additive, emulsion bulk absorption and scattering coefficients are simply given by

$$
K_{\mathrm{a}}=\sum_{\mathrm{m}} K_{\mathrm{a}, \mathrm{m}} \quad \text { and } \quad K_{\mathrm{s}}=\sum_{\mathrm{m}} K_{\mathrm{s}, \mathrm{m}}
$$

However, the same rationale should be carefully applied to the emission term in the transfer equation. A non-linearity arises because distinct solid species may be at different temperatures and the emission depends on the fourth power of those temperatures. Having this in mind, Eq. (12) for a plane-parallel heterogeneous polydispersed emulsion becomes

$$
\mu \frac{\mathrm{d} I}{\mathrm{~d} z}=-\left(K_{\mathrm{a}}+K_{\mathrm{s}}\right) I+\sum_{\mathrm{m}} K_{\mathrm{a}, \mathrm{m}} \frac{\sigma T_{\mathrm{SE}, \mathrm{m}}^{4}}{\pi}+\frac{K_{\mathrm{s}}}{4 \pi} G
$$

where $K_{\mathrm{a}}$ and $K_{\mathrm{s}}$ are given by Eqs. (25) and (26).

\section{Radiative heat transfer between solids in the emulsion: two-flux model}

The directional dependence of the radiation intensity remains to be solved and flux models may be employed in order to simplify the problem. The two-flux model relies on a semi-isotropic distribution of the radiation intensity, namely

$$
I(z, \mu)= \begin{cases}I^{-}(z) & , \quad-1<\mu<0 \\ I^{+}(z) & , \quad 0<\mu<+1\end{cases}
$$

Integration of Eq. (27) over each range of $\mu$ results in the following differential equations:

$$
\begin{array}{r}
\frac{1}{2} \frac{\mathrm{d} I^{+}}{\mathrm{d} z}=-\left(K_{\mathrm{a}}+K_{\mathrm{s}}\right) I^{+}+\sum_{\mathrm{m}} K_{\mathrm{a}, \mathrm{m}} \frac{\sigma T_{\mathrm{SE}, \mathrm{m}}^{4}}{\pi}+\frac{K_{\mathrm{s}}}{4 \pi} G \\
-\frac{1}{2} \frac{\mathrm{d} I^{-}}{\mathrm{d} z}=-\left(K_{\mathrm{a}}+K_{\mathrm{s}}\right) I^{-}+\sum_{\mathrm{m}} K_{\mathrm{a}, \mathrm{m}} \frac{\sigma T_{\mathrm{SE}, \mathrm{m}}^{4}}{\pi}+\frac{K_{\mathrm{s}}}{4 \pi} G
\end{array}
$$

Another consequence is that the incident radiation function $G$ may now be evaluated as

$$
G=2 \pi\left(I^{+}+I^{-}\right)
$$

As an initial approach, the two-flux method was applied in the bed section in order to obtain an alternative of Eq. (10) for the radiative heat transfer rate $E_{\mathrm{R}, \mathrm{SESE}, \mathrm{m}}$. Since $\nabla \cdot \vec{q}$ represents the thermal radiation balance within an emulsion volume element, the idea was to employ that term written for each solid species $m$. It is then assumed that

$$
E_{\mathrm{R}, \mathrm{SESE}, \mathrm{m}}=S_{\mathrm{E}} \nabla \cdot \vec{q}_{\mathrm{m}}=S_{\mathrm{E}} K_{\mathrm{a}, \mathrm{m}}\left(4 \sigma T_{\mathrm{SE}, \mathrm{m}}^{4}-G\right)
$$

where $S_{\mathrm{E}}$ is the emulsion sectional area (including interstitial gas) at bed height $z$. This equation represents a balance between emitted $\left(4 \sigma T_{\mathrm{m}}^{4}\right)$ and incident $(G)$ radiation for the $m$-type particles in an emulsion volume element of height equals to $\mathrm{d} z$. A schematic balance for a single particle is shown in Fig. 4.

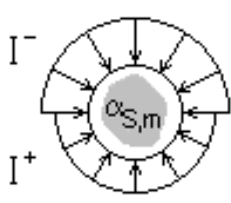

absorption

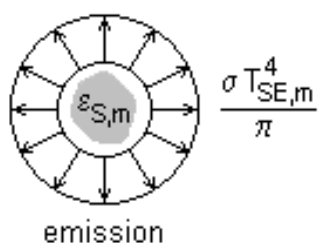

emission
Figure 4. Thermal radiation absorption by and emission from a $m$-type single particle.

Equations (31) and (32) show how solutions $I^{+}(z)$ and $\Gamma(z)$ are used to compute $E_{\mathrm{R}, \mathrm{SESE}, \mathrm{m}}$. Furthermore and as shown in Fig. 4, the thermal radiation balance is accomplished after integrating all involved intensities over a full $4 \pi \mathrm{sr}$ solid angle. For that, the assumption $\varepsilon_{\mathrm{S}, \mathrm{m}}=$ $\alpha_{\mathrm{S}, \mathrm{m}}$ is applied.

\section{Adaptation to the former simulation model: radiative equilibrium}

Applying the physical-mathematical condition stated by Eq. (11) to Eq. (32), the following result arises:

$$
\sum_{\mathrm{m}=1}^{3} E_{\mathrm{R}, \text { SESE }, \mathrm{m}}=\sum_{\mathrm{m}=1}^{3} S_{\mathrm{E}} \frac{\mathrm{d} q_{\mathrm{m}}}{\mathrm{d} z}=0 \Rightarrow \sum_{\mathrm{m}=1}^{3} \frac{\mathrm{d} q_{\mathrm{m}}}{\mathrm{d} z}=\frac{\mathrm{d} q}{\mathrm{~d} z}=0
$$

In the literature (Brewster, 1992; Modest, 1993), this condition is referred to as radiative equilibrium and it is useful when thermal radiation is the dominant mode of heat transfer. Nevertheless, conduction and convection are incorporated as well into the heat source (or sink) term. As commented by Modest (1993), "the inclusion of a volumetric heat source allows the treatment of conduction and convection 'through the back door' ". Therefore, the solution becomes an iterative process due to the mutual dependence among the temperature profiles and the heat source (sink) terms.

If Eq. (33) is valid for all bed positions, it can be shown with the help of Eqs. (31) and (32), that $I^{+}(z)$ and $I^{-}(z)$ are no longer independent, but related to each other according to

$$
I^{+}(z)+I^{-}(z)=\frac{2 \sigma}{\pi} \frac{1}{K_{\mathrm{a}}} \sum_{\mathrm{m}} K_{\mathrm{a}, \mathrm{m}} T_{\mathrm{SE}, \mathrm{m}}^{4}
$$

It should be mentioned that the above condition holds for the two-flux approximation. Therefore, only Eq. (29) should be included in the computational procedure. Temperature profiles of each solid species are found by solving Eq. (1). There, the summation $\sum E_{\mathrm{R}, \mathrm{SESE}, \mathrm{m}, \mathrm{n}}[\mathrm{Eq}$. (10)] should be replaced by $E_{\mathrm{R}, \mathrm{SESE}, \mathrm{m}}$, as given by Eq. (32), or 


\section{CIÊNCIA/SCIENCE}

$$
\begin{aligned}
F_{\mathrm{SE}, \mathrm{m}} c_{\mathrm{S}, \mathrm{m}} \frac{\mathrm{d} T_{\mathrm{SE}, \mathrm{m}}}{\mathrm{d} z}= & -E_{\mathrm{Q}, \mathrm{SE}, \mathrm{m}}-E_{\mathrm{M}, \mathrm{SEGE}, \mathrm{m}}-E_{\mathrm{C}, \mathrm{SEGE}, \mathrm{m}} \\
& -\sum_{\mathrm{n}=1}^{3} E_{\mathrm{C}, \mathrm{SESE}, \mathrm{m}, \mathrm{n}}-E_{\mathrm{R}, \mathrm{SESE}, \mathrm{m}} \\
& -E_{\mathrm{R}, \mathrm{SETD}, \mathrm{m}}-E_{\mathrm{R}, \mathrm{SEWD}, \mathrm{m}}
\end{aligned}
$$

Equations (29), (31), (32), (34) and (35) demonstrate the coupling suggested by Modest (1993).

\section{Boundary condition for the forward radiation intensity transfer equation}

Since all inlet particle temperatures $T_{\mathrm{SE}, \mathrm{m}}(0)$ are known, Eq. (34) applied at $z=0$ provides a condition for the sum $I^{+}(0)+I^{-}(0)$, namely

$$
I^{+}(0)+I^{-}(0)=\frac{2 \sigma}{\pi} \frac{1}{K_{\mathrm{a}}} \sum_{\mathrm{m}} K_{\mathrm{a}, \mathrm{m}} T_{\mathrm{SE}, \mathrm{m}}^{4}(0)
$$

A further relation between these two quantities can be obtained with the help of an imaginary radiating gray surface at temperature $T_{\mathrm{im}}$, with emissivity $\varepsilon_{\mathrm{im}}$ and reflectivity $\rho_{\mathrm{im}}$. Such a surface lies just above the distributor plate, whose corresponding properties $T_{\mathrm{d}}, \varepsilon_{\mathrm{d}}$ and $\rho_{\mathrm{d}}$ are known. This upper surface may correspond to a first layer of the emulsion, as sketched in Fig. 5.

$$
\rho_{\mathrm{im}}, \varepsilon_{\mathrm{im}}, \mathrm{T}_{\mathrm{im}} \frac{\text { imaginary surface }}{\mathrm{J}_{\mathrm{d}}=\varepsilon_{\mathrm{d}} \sigma \mathrm{T}_{\mathrm{d}}^{4}+\rho_{\mathrm{d}} \mathrm{H}_{\mathrm{d}}}
$$

Figure 5. Radiative heat transfer between two planeparallel, gray and isothermal surfaces.

Both surfaces are assumed to be diffusely emitting and reflecting opaque. This is a typical thermal radiation exchange problem between two infinite parallel flat surfaces facing each other. Writing the radiosities $J_{\mathrm{d}}$ and $J_{\text {im }}$ for each surface and identifying the intensity $I^{+}(0)$ to the irradiation $H_{\mathrm{im}}$, and the intensity $\Gamma(0)$ to the irradiation $H_{\mathrm{d}}$ (which is reasonable, since the separation distance is very small), the following relations should hold (Goldstein Jr., 1988):

$$
\begin{gathered}
I^{+}(0)=\frac{\varepsilon_{\mathrm{d}} \sigma T_{\mathrm{d}}^{4}+\left(1-\varepsilon_{\mathrm{d}}\right) \varepsilon_{\mathrm{im}} \sigma T_{\mathrm{im}}^{4}}{\pi\left[1-\left(1-\varepsilon_{\mathrm{d}}\right)\left(1-\varepsilon_{\mathrm{im}}\right)\right]} \\
I^{-}(0)=\frac{\varepsilon_{\mathrm{im}} \sigma T_{\mathrm{im}}^{4}+\left(1-\varepsilon_{\mathrm{im}}\right) \varepsilon_{\mathrm{d}} \sigma T_{\mathrm{d}}^{4}}{\pi\left[1-\left(1-\varepsilon_{\mathrm{d}}\right)\left(1-\varepsilon_{\mathrm{im}}\right)\right]}
\end{gathered}
$$

Values for $\varepsilon_{\text {im }}$ and $T_{\text {im }}$ should be such that, after their substitution into the above equations along the corresponding distributor parameters, the intensities $I^{+}(0)$ and $I^{-}(0)$ do satisfy Eq. (36). Nevertheless, their definitions are unnecessary because few algebraic manipulations involving the above relations and Eq. (36) lead to the following boundary condition:

$$
I^{+}(0)=\frac{\sigma}{\pi}\left[\frac{2\left(1-\varepsilon_{\mathrm{d}}\right)}{2-\varepsilon_{\mathrm{d}}} \frac{1}{K_{\mathrm{a}}} \sum_{\mathrm{m}} K_{\mathrm{a}, \mathrm{m}} T_{\mathrm{SE}, \mathrm{m}}^{4}(0)+\frac{\varepsilon_{\mathrm{d}} T_{\mathrm{d}}^{4}}{2-\varepsilon_{\mathrm{d}}}\right] \text { (39) }
$$

\section{J. A. Rabi et al. Incorporation of a Two-Flux...}

which is independent of $T_{\mathrm{im}}$ and $\varepsilon_{\mathrm{im}}$.

The distributor temperature $T_{\mathrm{d}}$ is calculated by an iterative process, which has been used since the early versions of the program (de Souza-Santos, 1987). The procedure is based upon an empirical correlation developed by Zhang and Ouyang (1984).

\section{CONCLUDING REMARKS}

As shown, the mathematical model for the radiative heat transfer between all solid species in the bed section of a fluidized bed has been reformulated. For this region, a new first-order ordinary differential equation was incorporated to the simulator. That equation governs the variation of the forward radiation intensity. Its solution allows the computation of thermal radiation exchange rates between particles in the emulsion. The associated boundary condition and auxiliary expressions were also implemented in the computational program. Numerical results are presented and assessed in next part of the paper.

\section{ACKNOWLEDGEMENT}

The authors are grateful to FAPESP - Fundação de Amparo à Pesquisa do Estado de São Paulo, for their financial support to the present research project (process no. 98/02891-8). 
CIÊNCIA/SCIENCE

\section{REFERENCES}

Brewster, M.Q., 1992, "Thermal radiative transfer and properties", John Wiley \& Sons, New York, USA.

Brewster, M.Q., Tien, C.L., 1982, "Radiative transfer in packed fluidized beds: dependent versus independent scattering", ASME J. Heat Transfer, Vol. 104, pp. 573-579.

de Souza-Santos, M.L., 1987, "Modeling and Simulation of Fluidized-Bed Boilers and Gasifiers for Carbonaceous Solids", Ph.D. Thesis, University of Sheffield, Department of Chemical Engineering and Fuel Technology, England.

de Souza-Santos, M.L., 1989, "Comprehensive Modeling and Simulation of Fluidized-Bed Boilers and Gasifiers", Fuel, Vol. 68, pp. 1507-1521.

de Souza-Santos, M.L., 1992, "Application of Comprehensive Simulation to Pressurized Fluidized-Bed Hydroretorting of Shale", Eastern Oil Shale Symposium, Lexington, Kentucky, USA.

de Souza-Santos, M.L., 1993, "Comprehensive Modeling and Simulation of Fluidized-Bed Reactors Used in Energy Generation Processes, Meeting on Energy Modeling Optimizing Information and Resources, IGT Institute of Gas Technology, Chicago, USA.

de Souza-Santos, M.L., 1994, "Application of Comprehensive Simulation to Pressurized Fluidized-Bed Hydroretorting of Shale", Fuel, Vol. 73, No. 9, pp. 14591465.

de Souza-Santos, M.L., 1995, “Application of Comprehensive Simulation of Fluidized-Bed Reactors to the Pressurized Gasification of Biomass", J. of the Braz. Soc. Mechanical Sciences, Vol. XVI, No. 4, pp. 376-383.

de Souza-Santos, M.L., 1996, "Otimização Teórica e Testes Experimentais Preliminares de Gaseificação de RASF em Leito Fluidizado", IPT - Instituto de Pesquisas Tecnológicas do Estado de São Paulo, Report no. 34.926/DME/AET.

de Souza-Santos, M.L., 1997, “A Study on Pressurized Fluidized-Bed Gasification of Biomass through the Use of Comprehensive Simulation", Proceedings of the 4th International Conference on Technologies and Combustion for a Clean Environment, Lisboa, Portugal, Vol. 2, section 25.2, pp. 7-13.

de Souza-Santos, M.L., 1998, “A Study on Pressurized Fluidized-Bed Gasification of Biomass through the Use of Comprehensive Simulation", In: "Combustion Technologies for a Clean Environment", chapter 4, Gordon and Breach Publishers, Amsterdam, Holland.

de Souza-Santos, M.L., 1999, “A Feasibility Study on an Alternative Power Generation System Based on Biomass Gasification/Gas Turbine Concept", Fuel, Vol. 78, pp. 529-538.

Geldart, D., 1986, "Gas Fluidization Technology”, John Wiley \& Sons, New York, USA.

Goldstein Jr., L., 1988, "Elementos de radiação térmica", UNICAMP - Universidade Estadual de Campinas, Publ. FEC 04/88, Campinas, Brazil.

Kunii, D., Levenspiel, O., 1969, "Fluidization Engineering", John Wiley \& Sons, New York, USA.

Modest, M.F., 1993, "Radiative heat transfer", McGraw-Hill, New York, USA.

Shafey, H.M., Abd El-Ghany, A.M., Nassib, A.M., 1993, "An analysis of the combined conductive-radiative heat transfer between a surface and a gas-fluidized bed at
J. A. Rabi et al. Incorporation of a Two-Flux...

high temperature", Int. J. Heat Mass Transfer, Vol. 36, No. 9, pp. 2281-2292.

Tien, C.L., 1988, "Thermal radiation in packed and fluidized beds", ASME J. Heat Transfer, Vol. 110, pp. 1230-1242.

Zhang, G.T., Ouyang, F., 1985, Heat transfer between the fluidized bed and the distributor plate, Ind. Eng. Chem. Process Des. Dev., Vol. 24, pp. 430-433. 